\title{
Communicating astronomy by the Unizul Science Centre
}

\author{
A. Beesham ${ }^{1}$ and N. Beesham ${ }^{2}$ \\ ${ }^{1}$ Department of Mathematical Sciences, University of Zululand, Kwa-Dlangezwa 3886, \\ South Africa, email: abeesham@pan.uzulu.ac.za \\ ${ }^{2}$ Paul Sykes Primary School, Earlsfield, Durban 4037, South Africa
}

The University of Zululand, situated along the east coast of KwaZulu-Natal, has a thriving Science Centre (USC) situated in the developing port city of Richards Bay. Over 30000 learners visit the centre annually, and it consists of an exhibition area, an auditorium, lecture areas and offices. The shows consist of interactive games, science shows, competitions, quizzes and matriculation workshops. Outreach activities take place through a mobile science centre for schools and communities that cannot visit the centre.

The USC offers a programme in astronomy both at the centre as well as outside upon request to nearby areas. This 4 hour show has to be booked in advance. It is usually booked by schools, but also by old age homes and for birthday parties, etc. Roughly 3 shows per month are held. The programme involves looking at the southern skies in an inflatable Starlab planetarium (Zululand's only one) where about 30 people can be accommodated, a tour of the USC, analemmatic sundial, telescopes, optics, history of South African space science and an astronomy quiz game. In addition, one of the following award-winning shows can be selected: the solar system, powers of 10 (distances in astronomy), science of astronomy, from Sputnik to Sumbandila science show, robotics in space or the earth and the sun.

The USC hosts a regional Astro Quiz, which is an astronomy competition run nationally by the South African Agency for Science \& Technology Advancement. It is aimed at grade 7 primary school learners, who are sent material and then asked questions. The school with the most points is the winner and then goes on to participate at national level.

A unique feature of our USC is the incorporation of indigeneous knowledge (IK). Mr Mdumiseni Nxumalo, who is in charge of the astronomy shows, uses IK to help develop a better understanding of astronomy. He endeavours to communicate astronomy through an IK approach. Many constellations are named from a northern "western" perspective and in the southern hemisphere make little sense to many people. The USC shows now describe traditional star lore, e.g., the appearance of Pleiades marks the beginning of the ploughing season. Such an IK approach has elicited a positive response from visitors, who now want more traditional astronomy. The USC plans to build a planetarium in the shape of a traditional Zulu beehive hut, which will be unique in the world.

The USC works on the idea that they use only aspects of IK that form part of science, and not myths, etc, extracting relevant aspects that encourage science literacy and scientific thinking. The view is adopted that both science and IK can work together in communicating astronomy (and science in general) more effectively to the public. 